Original Article

\title{
A clinical study of adherence of candida albicans to an improved NBR denture soft lining material
}

\author{
Naeem Ahmed ${ }^{1}$, Aruna J. Bhandari ${ }^{2}$, Arti Saluja Sachdev ${ }^{3}$, Farah Khan ${ }^{4}$, \\ Shitanshu Malhotra ${ }^{5} \&$ Taseer Bashir ${ }^{6}$
}

${ }^{1}$ Senior Lecturer, Department of Prosthodontics, ${ }^{3}$ Senior Lecturer, Department of Oral M edicine, ${ }^{5}$ Senior Lecturer, Department of Public Health Dentistry, ${ }^{6} \mathrm{PG}$ Student, Department of Oral M edicine, CPGIDS\&H. Lko,

${ }^{2}$ Dean and Professor, Rural Dental College, Loni. M aharashtra, ${ }^{4}$ PG Student, Department of Prosthodontics, Kothiwal Dental College, M oradabad.

\author{
Correspondence \\ Naeem Ahmad \\ Senior Lecturer, Department of Prosthodontics, Career Post-Graduate Institute of Dental Sciences, Lucknow, India. \\ Mobile : +919415142227 E-mail : naeem_bds@yahoo.co.in
}

\begin{abstract}
30 dentures selected for the study were disinfected using effervescent denture tablets. Then the dentures were trimmed $1.5 \mathrm{~mm}$ from fitting surface and relined with NBR soft lining material. Sample was scraped from denture fitting surface after one month and two months duration and the changes in colony forming units per mm after each month's time were measured and marked. After one month's duration, 24 samples were reported sterile and 6 showed colonies of Candida albicans \& Staphylococcus aureus. After 2 months duration, 28 out of 30 samples became positive with C. albicans $\&$ S. aureus colonies and aerobic spore bearing units. NBR soft liner material was sterile till one month of clinical usage so it can be prescribed as a safe soft lining material till one month of clinical usage in a controlled environment of oral hygiene
\end{abstract}

Keywords: soft denture liner, heat cure denture, C. albicans, denture sore mouth.

\section{Introduction}

Completely edentulous patients with a lower pain threshold or with a thinner mucosal lining overlying the jawbone do not resist pressure applied through the denture well. During functional and parafunctional loading of such tissues, they get compressed between dense jawbone and non-resilient denture plastic, so a painful response is elicited So relining these hard surfaces with a soft denture liner will help to eliminate or reduce a painful tissue compression ${ }^{1}$.

So the indications for use of a resilient liner are existence of thin, non-resilient mucosal coverage of the residual ridge, poor ridge morphology Access this article online Quick Response Code

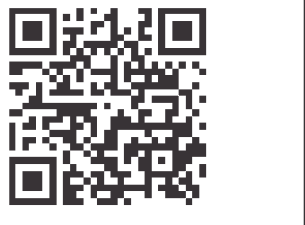
persistent denture-sore mouth and acquired or congenital oral defects.

Stoner (1962) stated that the rationale for using a soft lining material is that part of the energy transferred from it to the denture which aids in deforming the denture elastically and consequently reduces the direct load of mastication on the atrophied area. In addition, the soft lining produces an equal amount of pressure over the bone of the ridge and thereby avoids resistance from the prominent spicules to a larger amount of applied force.

Fungi are recognized as one of the major pathogens in critically ill and debilitating patients. Candida species are the fourth leading cause of bloodstream infections in the U.S. and disseminated candidiasis has a report of $25 \%$ mortality rate. Among Candida species, C. albicans is considered the most commonly isolated and responsible for majority of the superficial and systemic conditions².

A Study done at the University of Bristol Dental school in 2008 revealed that the best known fungal infections is thrush and is caused by Candida. It mainly involves warmer and moister areas like oral and genital area regions. It occurs both in healthy and debilitating persons but when the immune system is weak then it can be fatal. 
Now days, Candida has generated considerable interest from a Global health perspective according to a report generated through a funded project by the US National Institutes for Health (NIH). Candida albicans had shown its resistance behavior towards certain types of antimicrobial agents. So once they are inside the human body, it's very difficult to get rid of $i^{3}$. When Candida becomes pathogenic, it grows filaments known as hyphae that penetrate the body tissues. It can cause 'sore mouth' in denture users, where they grow in between the denture and the denture covering mucosa. While denture wearers can apply an anti-fungal paste to help get rid of the infection, they usually end up having to obtain new dentures because the hyphae penetrate the denture material.

\section{Characteristics of Soft Denture Liners}

The preferred materials for fabricating denture liners are special medical grade rubber or silicone-type compounds. The compressibility of silicone materials is more. For enhanced absorption of stresses, these materials must be reasonably thick ${ }^{4}$. In order to achieve this thickness, there has to be a space for soft liner material in the intaglio surface of a denture, which is obtained by removing certain amount of denture plastic from fitting surface. Soft denture liners tend to harden with the passage of time, as this stiffening effect is so very gradual so it goes undetected sometimes by the patient. But the patient's complaint increase with time until replaced by a newer soft denture liner. Denture liners are soft due to their porous nature. This porous nature contributes in their deterioration and holds microorganisms in their pores ${ }^{5}$.

Soft denture liner material colonization by dental plaque and fungi is easy. It leads to mucosal infections. Candida albicans is the microorganism that most frequently colonizes the soft denture liner intra-orally. This Colonization process occurs both within and on surface of denture liner.

\section{Advantages of Soft Denture Liners}

A soft denture liner provides a gentle denture fitting surface especially in individuals with a sensitive underlying oral mucosa. The soft denture liners possess a tendency to compress and conform to a constantly changing with time jawbone surface. No matter this definitely helps in the prevention of pain from a moderately unbalanced bite due to jawbone resorption, it is not a long-term substitute for the much needed regular denture adjustment follow-up ${ }^{6}$.

\section{Disadvantages of Soft Denture Liners}

Soft denture liners deteriorate continuously with time hence collect microorganisms quite easily. Therefore they must be replaced on a regular short term basis. As soft denture liners help to reduce pain from an uneven bite, patients may get a false sense of security, thinking their denture is adequately functioning while the bite continues to deteriorate with time. Routine dental check-ups are a must. Generally, soft tissue liners are more costly than a conventional hard denture liner.

\section{Care and Maintenance}

The denture surface with a soft Liner should not be cleaned by scrubbing with a hard denture brush to prevent its tearing. The use of soft denture brush under running water is recommended'.

\section{Statement of problem}

Soft lining materials continue to have a place in clinical removable Prosthodontics. However, there is an increased probability of fungal growth on soft lining materials. Colonization of denture soft lining materials by Candida albicans can result in clinical problems. Here a newly manufactured improved Nitrile Butadiene Rubber, (NBR MP Sai enterprises, Mumbai) was clinically tested for its adherence with fungal growth.

\section{Purpose of the study}

To study the candida adherence to NBR soft lining material and to determine the safe duration of its clinical usage.

\section{Inclusion Criteria}

- Subjects with dry mouth having diminished salivary secretion

- Subjects having pain during mastication with dentures

- Subjects with unhealthy mucosal conditions like inflammation, redness etc. 
- Mentally sound subjects who can follow proper oral hygiene protocol.

\section{Material and Methods}

NBR soft liner, Carbide trimming bur, Heat cure dentures, Pressure pot, silicone mixing jar, culture media, stereo microscope. All dentures selected were disinfected by using denture cleansing effervescent tablets; (Fittident). (See Fig.3). Then the dentures were trimmed $1.5 \mathrm{~mm}$ from fitting surface with help of depth orientation grooves and chair side relined by NBR soft lining material. Then the dentures were given back to the patients and instructions given. Sample of NBR was scraped from denture fitting surface after one month and two months duration and sent to the Dept. of Microbiology, CMC, Lucknow for incubation in Reinforced Clostridial Media (RCM). RCM medium is prepared by suspending 38 grams in 1 liter of distilled water. It was sterilised by autoclaving at $121^{\circ} \mathrm{C}$ for 15 minutes ${ }^{8}$, then stored overnight at $30^{\circ} \mathrm{C}$. The inoculated plates were incubated with gentle agitation (150 rpm) for $90 \mathrm{~min}$ at $37^{\circ} \mathrm{C}$ for adhesion to occur.

\section{Statistical analysis}

Independent paired Student's-'t' test. A ' $p$-value' of less than 0.05 was considered significant.

\section{Results}

Numbers of CFU's per ml were calculated, and the data was grouped and analyzed. After one month's duration of denture wear, 24 tested sterile (See Fig.4) and remaining 6 showed colonies of Candida albicans and Staphylococcus aureus. After 2 months duration of denture wear, 28 out of 30 samples became positive with C. albicans \& S. aureus colonies and aerobic spore bearing units. (See Fig.5)

\section{General conclusion}

NBR soft liner material was sterile till one month of clinical usage. So it can be prescribed as a safe soft lining material till one month of clinical usage in a controlled environment of oral hygiene.

\section{Future considerations}

What is the clinical observation after 1 and 2 months of denture wear: The greatest virtue of soft liners lies in their versatility and ease of use. Their biggest flaw is that they are so easily misused. Because the relined dentures provide immediate relief and comfort, there is a danger that the patient will wear them too long and so cause trauma to the supporting tissues thereby producing the very situation that their use is intended to prevent or correct. Their longevity in wear is very limited. They harden and roughen within four to eight weeks because of loss of the plasticizer. This requires close observation of the patient by the dentist. Hence more research is required in this field with emphasis on comparative analysis of various soft liners and to develop an ideal soft liner material for diverse clinical scenarios.

\section{Observation}

\begin{tabular}{|c|l|c|}
\hline S.No. & After one month & After two months \\
\hline 1 & STERILE & CFU \\
\hline 2 & STERILE & CFU \\
\hline 3 & STERILE & CFU \\
\hline 4 & CFU & CFU \\
\hline 5 & STERILE & CFU \\
\hline 6 & STERILE & CFU \\
\hline 7 & STERILE & STERILE \\
\hline 8 & CFU & CFU \\
\hline 9 & STERILE & CFU \\
\hline 10 & STERILE & CFU \\
\hline 11 & CFU & CFU \\
\hline 12 & STERILE & CFU \\
\hline 13 & CFU & CFU \\
\hline 14 & STERILE & CFU \\
\hline 15 & CFU & CFU \\
\hline 16 & STERILE & CFU \\
\hline 17 & CFU & CFU \\
\hline 18 & STERILE & STERILE \\
\hline 19 & STERILE & CFU \\
\hline 20 & STERILE & CFU \\
\hline 21 & STERILE & CFU \\
\hline 22 & STERILE & CFU \\
\hline 23 & STERILE & CFU \\
\hline 24 & STERILE & CFU \\
\hline 25 & STERILE & CFU \\
\hline 26 & STERILE & CFU \\
\hline 27 & STERILE & \\
\hline 28 & STERILE & STERILE \\
\hline 29 & STERILE & CFU \\
\hline 30 & & CFU \\
\hline
\end{tabular}


Table No. 1 : Growth of microorganisms on resin denture surface after different Time Periods

\begin{tabular}{|l|c|c|c|c|c|c|}
\hline Duration & Sample & $(+)$ & $(-)$ & Mean & SD & P value \\
\hline After one month & 30 & 06 & 24 & 340 & 387 & $P>0.05$ \\
\hline After Two month's & 30 & 28 & 02 & 14,100 & 6889 & $P<0.05$ \\
\hline
\end{tabular}

$\mathrm{CFU}=$ Colony Forming Units

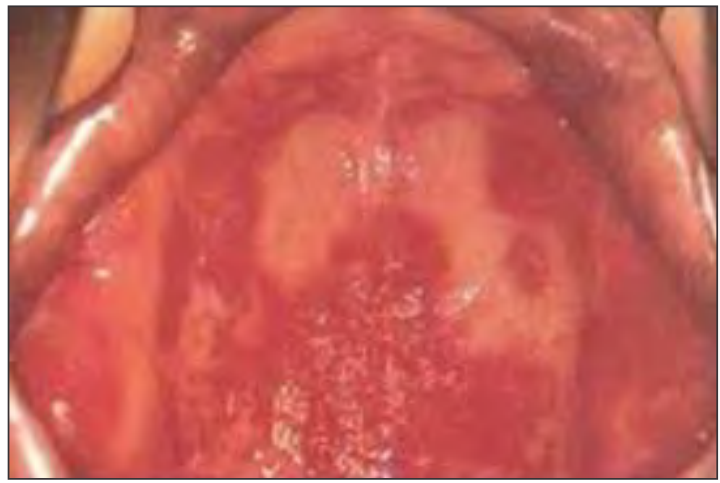

Fig.1 : Mucosal redness

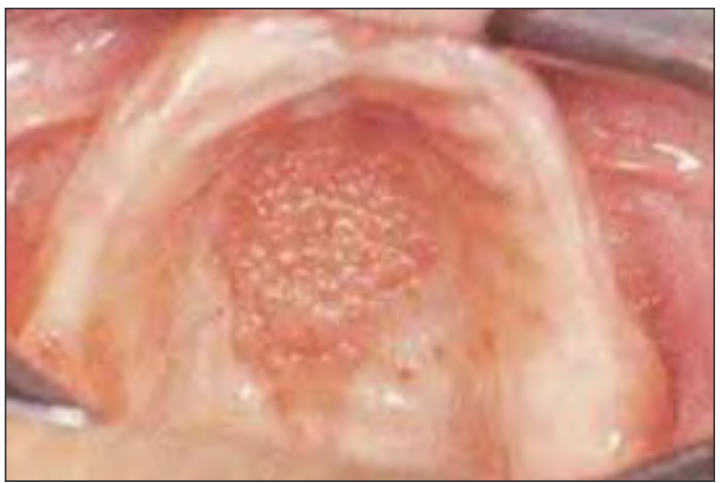

Fig.2 : Mucosal inflammation

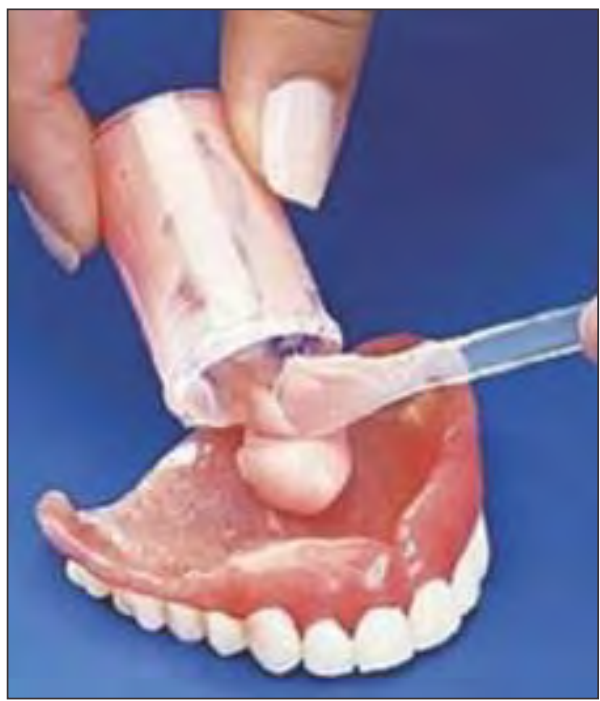

Fig.3 : Denture relining

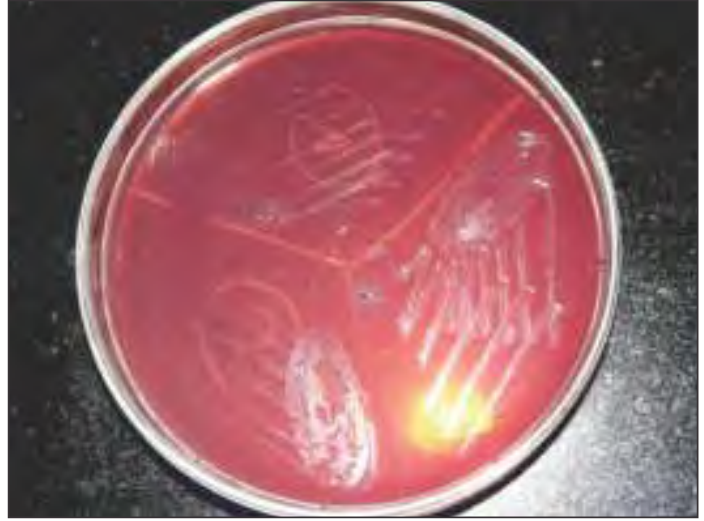

Fig.4 : Sample after 1 month

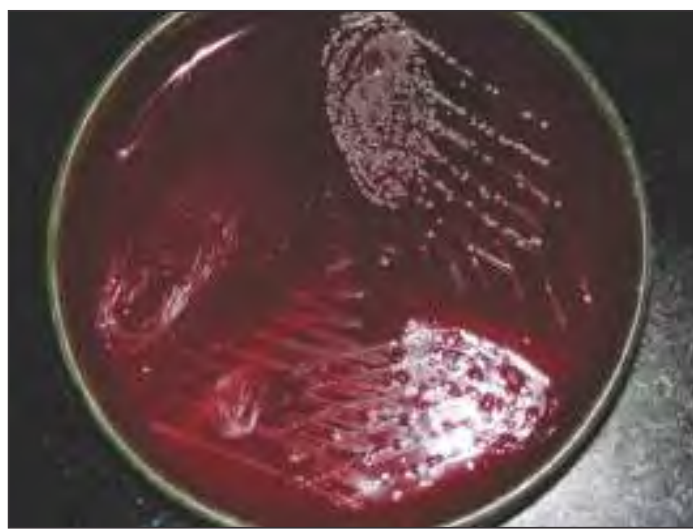

Fig.5 : Colony after 2 months

Institutional Ethical Committee: Approval was granted from Institutional research cell

Subject Consent: All the subjects were duly informed and consent was taken in prior.

\section{References}

1. "Nikawa H, Chen J, Makihira S. Interactions between thermal cycled resilient denture lining materials, salivary and serum pellicles and Candida albicans in vitro. Part II. Effects on fungal colonization. J. Oral. Rehabil., 27:124-3, (2000)."

2. "Egusa H, Hamada T, Kumagai H. Biofilm formation of Candida albicans on the surface of denture lining materials caused by denture cleansers in vitro., J. Oral. Rehabil. ; 30:243-50, (2003)."

3. "JC Junqueira, BB Fuchs, M. Muhammed. Oral Candida albicans isolates from HIV-positive individuals have similar in vitro biofilmforming ability and pathogenicity as invasive Candida isolates. BMC microbiology., 11:247-51, (2011)."

4. "Bulad K, Taylor RL, Verran J. Colonization and penetration of denture soft lining materials by Candida albicans. Dent. Mater., 20:167-75, (2004)."

5. "Tari BF, Nalbant D, Dogruman F. Surface roughness and adherence of Candida albicans on soft lining materials as influenced by accelerated aging. J. Contemp. Dent. Pract., 8:18-25, (2007)."

6. "Taylor RL, Bulad K, Verran J. Colonization and deterioration of soft denture lining materials in vivo. Eur. J. Prosthodont. Restor. Dent. 16:50-5, 2008."

7. "Pavan S, Filho JN, Spolidorio DM. Colonisation of soft lining materials by micro -organisms. J. Gerontology., 27:211-6, (2010)."

8. "Fan C, Chu L, Rawls HR. Development of an antimicrobial resin-A pilot study. Dent. Mater., 27:322-8, (2011)." 